\title{
Enhancing ESL Learners' Vocabulary Learning of Metaphorically-used Words
}

\author{
Leonardo Veliz \\ Deakin University, Melbourne, Australia
}

\begin{abstract}
The present study examined the role of awareness of metaphor in learners' lexical learning. A total of 35 intermediate English as second language (ESL) students participated in this study. Participants were randomly divided into two small groups. One $(N=17)$ served as the control group and the other $(N=18)$ as the experimental group. Both groups were taught several metaphorically-used expressions over a period of six weeks. The groups differed in that the experimental group received systematic and explicit explanations of the source and target relationships that underlie metaphor, while the control group did not receive such instruction. Pre-tests and Post-tests were administered in order to measure lexical understanding of metaphorical items. Two journal entries were given out to students at two different intervals throughout the teaching period in order to tap into their views of how their lexical understanding of metaphor was changing, or not changing, over time. Results revealed that those students who received systematic and explicit explanations on the concrete experiential basis of metaphor showed greater understanding of metaphorical meanings, and seemed more inclined to unpacking their metaphoricity by looking at what lies behind them.
\end{abstract}

Index Terms - lexical learning, metaphor, metaphor awareness, cognitive linguistics

\section{INTRODUCTION}

It is commonplace that vocabulary learning is central to the development of learners' English language skills. Its centrality has driven burgeoning research into several areas such as the interplay between vocabulary and incidental learning (e.g. Huckin \& Coady, 1999; Wode, 1999), vocabulary learning and extensive reading (e.g. Nation, 2015), the rate of vocabulary learning and retention (e.g. Waring \& Takaki, 2003), and the role of collaboration in vocabulary learning (e.g. Dobao, 2014), just to mention a few.

With the proliferation of Corpus Linguistics and popularity of the lexical approach in the 1990's, the centrality of lexis has had unprecedented implications for language learning and teaching. The inclusion and implementation of the lexical approach in our teaching practices has enabled us to view language teaching and learning from a different angle. Unlike traditional teaching approaches that have widely promoted a grammar-lexis dichotomy, the lexical approach puts forward the idea that although grammar and lexis are intertwined, lexis is fundamental in creating meaning, and grammar is subservient to lexis. In this way, it is understood that language is grammaticalised lexis, not lexicalised grammar (Lewis, 1993). The immediate pedagogical implication of this principle is that more time should be spent on helping learners develop their stock of phrases, and less time on the teaching of rules and patterns.

As far as the teaching of vocabulary is concerned, language teachers very often have to make momentous, and sometimes difficult, decisions about what in a word should be taught. Nation's (2001) description of what is involved in a word highlights three key elements of lexical knowledge: form, meaning and use. Not only do these elements have implications for what learners should be learning about a new lexical item, but also for what should be taught to promote successful lexical learning. Additionally, several other scholars (e.g. Milton, 2009; Nassaji, 2004; Nation, 2001; Read, 2000) have distinguished two fundamental dimensions of vocabulary knowledge - vocabulary breadth and vocabulary depth. The former, also referred to as vocabulary size, alludes to the number of words a person knows (Milton, 2009; Nation, 2001). The latter, sometimes known as quality of vocabulary knowledge, makes reference to several aspects of word knowledge that are central to adequate and successful use of lexicon in communication (Nowbakht, Moinzadeh, \& Dabaghi, 2015, p. 249). Some of these aspects include knowledge of spelling, pronunciation, register, frequency, collocational patterns and meaning.

English language teachers generally show considerable expertise in teaching these features quite successfully. However, there are certain intricate features of language that tend to cause great barriers to the effective delivery of vocabulary instruction. One of these concerns itself with meaning, especially metaphorical meanings of words.

Dealing with meaning usually seems unproblematic to language teachers. However, as Guo (2007, p. 153) points out, the adequate and successful teaching strategies to teach metaphorical meanings to second language learners are always difficult to come by. Different teachers use different strategies to the presentation of the metaphorical or, in general, the figurative content of lexis. While some are in search of approaches to introduce learners to the systematicity of metaphorical meanings, others continue to rely solely on traditional ways which view meaning as arbitrary. 
The present study is grounded on the view that a great deal of the metaphorical content of lexis is motivated by systematic patterns of thought that are rooted in our bodily experiences. This is in line with the tenets of the theory of conceptual metaphor (CM) from Cognitive Linguistics (CL), approach which underpins the present study.

\section{LeXICAL LEARNING, METAPHOR AND AwARENESS OF METAPHOR}

It is commonly accepted that lexical learning is a central part of mastering a second language (Schmitt, 2008). Several researchers (e.g. Nation, 2001; Nation, 2015; Nowbakht et al., 2015) have acknowledged the centrality of vocabulary to communication and understanding each other. Some have gone further to state that 'lexis is the core or heart of language' (Lewis, 1993, p. 89). Moreover, Wilkins (1972) pointed out that while little meaning can be conveyed without grammar, no meaning at all can be conveyed without vocabulary.

The nature of words can be of two forms: literal or figurative (Deignan, 1999). Each of these categories has their own features. In Truth-Conditional semantics, words with literal content are statements that refer to phenomena that are true with respect to reality (Carston, 2011). By contrast, figurative words are those that seem semantically defective in that they are not truthful in relation to the world. From a psycholinguistic point of view, literal and figurative language are thought be processed differently. Literally-intended words are said to be processed automatically while the processing of metaphorically-used words is presumably slower (Glucksberg, 2003). Irrespective of the possible processing differences, what is important to stress is that sufficient evidence has demonstrated that our lexicon is largely figurative, particularly metaphorical, hence its centrality to language teaching and learning.

The significance of vocabulary to second language pedagogy has given rise to several theories, techniques and teaching approaches aimed at achieving good vocabulary learning. Traditional theories of vocabulary learning suggest that frequency of encounters with words is an essential factor affecting learners' lexical development (Anderson, 1982; Hulstijin, 2001). Elgort and Warren (2014) point out that this frequency view of vocabulary learning also accounts for context word learning in texts. This means that greater occurrence of a word within the context of a text is likely to affect lexical learning. This frequency theory of word learning may prove useful for literally-used words, not for metaphorically-intended ones. This is particularly because literal meanings tend to be much more concrete, salient and familiar than metaphorical meanings (Giora \& Fein, 1999). This suggests that greater occurrence of a literal word in a sentence or text is likely to enhance its saliency which may therefore help learners develop more familiarity with its meaning in context. However, this frequency-based view of word learning may not be of any use to learners or readers having multiple encounters with metaphorically-used words. Giora and Fein (1999) point out that metaphoric words are more abstract and less salient than literal ones, thus imposing a cognitive burden on learners (Kalyuga \& Kalyuga, 2008).

Another widely-used approach to vocabulary learning rests on the belief that the context within which the word occurs affects lexical learning (Elgort \& Warren, 2014, p. 367). This belief assumes that a greater number of contextual clues would help learners guess the meaning of unknown words from context. There are, however, several studies that point to the fact that words that are easier to guess are also easier to forget (e.g. Borovsky, Kutas, \& Elman, 2013; Frishkoff, Collins-Thompson, \& Perfetti, 2008). The conflicting issue with the view of guessing meaning from context is that availability of contextual clues may assist learners in guessing or inferring meaning of unknown words, strategy that can support word retention in the short term, but not necessarily lead to vocabulary learning in the long term (Elgort \& Warren, 2014).

Although research into the two above-mentioned approaches to vocabulary learning, the frequency-based and contextual clue views, has not overtly indicated their suitability and adaptability to the learning of words with metaphorical content, one could infer that, based on their basic tenets and assumptions, the learning of metaphorical vocabulary is by no means constrained to the number of encounters learners may have with an unknown word or the contextual affordances to guess or infer its meaning in context. Learning metaphorical words requires an approach that enables learners to understand the systematicities behind the relationships between the different domains involved in the metaphor.

A relatively recent theory that has sparked the interest of scholars wishing to investigate vocabulary teaching and learning in systematic ways is Cognitive Linguistics (CL). CL is not a single unified theory; rather, it is a multidisciplinary approach to language and language learning that comprises a set of different approaches. One of the most of fundamental and well-developed approaches to language is what is known as the "Conceptual Metaphor Theory' (CMT) (Evans \& Green, 2006).

To properly understand the origins of the theory along with its contributions, it is of great importance to recall what the context was like within which the theory emerged. Prior to the emergence of the CMT, there was the belief, primarily promoted and supported by the philosophy of language, poetry and literature, that metaphor was a property of, and very often a problem for, language (Katz, Cacciari, Gibbs, \& Turner, 1998). In this way, metaphor was commonly referred to as a linguistic device primarily serving ornamental and decorative functions in language, particularly in poetry (Steinberg, 1999). This relatively narrow view clearly showed some of the limitations and constrains of metaphor as being linked solely to a feature of language.

Challenged by the proponents of the CMT, such constrained belief was taken a step further. Lakoff and Johnson (1980a) pointed out that metaphor is not just a matter of language; metaphor is pervasive in everyday activities in life 
and permeates not only language but also thought. In other words, they put forward the idea that metaphor is by no means a device of poetic imagination and rhetorical flourish; that is, it is not a characteristic of language alone. On the contrary, and most importantly, it was pointed out that people can't get along well without metaphor as it is pervasive tool that manifests itself in both how people talk how they think and structure concepts in their minds.

This is precisely the central idea that forms the basis of the CMT. As put forward by Lakoff and Johnson (1980a, 1980b, 1999) and Evans and Green (2006), the central tenet of the CMT can be summarized as a theory in contemporary cognitive science which regards metaphor as a significant constituent of human cognition. What's interesting to highlight about this view, though, is that metaphor, from a CMT perspective, does not simply reside in the individual's mind. In other words, it is not a phenomenon that originates in the mind and finishes in the individual's speech. On the contrary, metaphor arises from our early physical, bodily and sensorimotor experiences with the outside world . This is precisely what forms the basis of the CMT; that metaphor is not simply a stylistic or ornamental device of language; rather, it is something that permeates the ways in which individuals reason and conceptualise the world. What this suggests is that all the reasoning we do and language we express, which are rooted in our minds, have emerged from our early experiences in the world, particularly from our sensorimotor and bodily interactions with the concrete reality.

Pedagogical applications of the CMT to the teaching of metaphorical vocabulary have been primarily in the direction of raising language learners' awareness of the underlying patterns of metaphors. Several studies have shown that knowledge of conceptual metaphor and of its patterning has a positive effect on students' ability to acquire vocabulary (e.g. Beréndi, Csábi, \& Kövecses, 2008; Boers, 2004; Charteris-Black, 2000; Deignan, Gabrys, \& Solska, 1997; Gao \& Meng, 2010; Kövecses \& Szabo, 1996). For example, Gao and Meng (2010) investigated the extent to which an enhanced awareness of metaphor could help English as a Foreign Language (EFL) learners acquire and retain vocabulary. The investigation is a traditional experimental study in which a control and an experimental group were utilised throughout the course of the experiment. Each of the groups received a different kind of teaching intervention. The control group went through, what the authors have labelled, 'The Traditional Teaching Model of Metaphorical Expressions' while the experimental group went through 'The Teaching Model Focusing on the Enhancement of Metaphor Awareness'. The former involved the grouping and presentation of metaphorical words according to their pragmatic and functional usages. The latter involved the grouping and presentation of metaphorical words according to a shared metaphorical theme which was "to enhance the learners' metaphor awareness" (2010). This methodological procedure, in which chunking and presenting words on the basis of common metaphorical themes, seems to be facilitative of and conducive to the development of metaphor awareness to learn metaphorical language.

Having adopted a similar methodology, the present study is grounded on the premise that an enhanced awareness of metaphor contributes to language learners' development of lexical learning of metaphorical words.

\section{Methodology AND Methods}

The methodology utilised in this study falls within what has been traditionally called mixed methods (Cohen, Manion, \& Morrison, 2007; Creswell, 2003). The rationale for using a mixed methodology lies in the benefits of what Dawson (2009) calls 'triangulation'. The advantages, in her view, of using and combining two seemingly distinct research paradigms relate to how the weaknesses in both quantitative and qualitative research can be counteracted. In a similar vein, Creswell (2003) points out that the combination of both quantitative and qualitative approaches in a study can yield much richer data and therefore enable the researcher to look at the phenomenon of study from different interrelated perspectives.

In the present study, the inclusion and combination of these two methodological approaches became manifest in the methods utilized for data collection and the ways in which the data were analysed. As described in 4.1, two methods were used in the data collection process of this study. The quantitative tool was a vocabulary test while the qualitative instruments comprised journal entries.

The data for this study derives mainly from two data sets. One is a vocabulary test aimed at measuring learners' understanding of metaphorically-used words. The test was administered before and after the teaching intervention period.

In regard to the composition of the test, it had three items that attempted to measure students' understanding of lexical metaphors in different ways. The first two items were intended to measure learners' understanding of single metaphorical words while the last item focused on idioms. The first section was a multiple-choice section that included 10 lexical items presented in the context of sentences. The lexical items were in bald to deliberately draw students' attention to them. For each sentence students had to indicate whether the word in bold was 'literal' or 'metaphorical'. Most of the lexical items were single words, others were multi-word units, especially complex prepositions. The second section was a fill-in the gaps activity, while the last was a short-answer section. It is worth noting that the same test was administered before and after the intervention period to both groups. As a result, none of the metaphorically-used lexical items in the test were utilized in the teaching intervention in order to avoid familiarity with the items being a possible influence on learners' scores in the posttest. To ensure that pretest scores did not influence the results of the posttest, no feedback whatsoever was given to students until the end of the intervention program. 
The other data set was a journal entry that was given to both groups, controlled and experimental, on two different occasions during the teaching intervention. The journal entry had two questions that were intended to tap into learners' views of the possible impact of the teaching on their perceptions of learning metaphorical vocabulary. The questions in journal entry 1 were as follows:

1. How easy or difficult has it been for you to understand metaphorical words?

2. In what ways have the teaching sessions helped you better understand metaphorical words?

The questions in journal entry 2 were similar. Only one question differed with respect to the questions in journal entry 1:

1. In what ways have the teaching sessions helped you better understand metaphorical words?

2. Have your perceptions of learning metaphorical words changed over time?

\section{A. Participants}

35 ESL students participated in this study. Students participated voluntarily in a five-week teaching period, which would focus on vocabulary learning. All 35 participants were given a consent form that provided a brief description of the study and information on the confidentiality of their identity. The participants were all upper-intermediate students undertaking an English for Academic Purposes (EAP) class, and came from culturally and linguistically diverse backgrounds whose first languages (L1s) were Korean, Chinese, Japanese, Thai, Spanish and Italian.

For the purpose of the teaching intervention period, the total group of participants was randomly divided into two groups of 17 and 18. Students were invited to attend a one-hour session, after their normal class timetable, twice a week. The teacher-researcher met each of the groups on the same days at different times.

\section{B. Data Analysis}

As already mentioned, two data sets were utilised in this study where one, the vocabulary tests, was quantitative while the other, the two different interviews, was qualitative. As far as the quantitative data set, the two vocabulary tests were marked and the scores pertaining to each of the test items were entered in an Excel Spreadsheet in order to compute basic statistical values, namely Mean and Standard Deviation, and also to represent the data in graphs. Additionally, for the sake of statistical significance, the results of both the experimental and control groups were compared by conducting an independent-samples t-test.

The analysis of the journal entries was assisted and facilitated by QSR NVivo 10, a software used for qualitative analysis. Once entries were entered into NVivo, the data was coded and analysed for recurrent patterns. These patterns were further analysed in search of emerging themes in the data.

\section{The Teaching Intervention Period}

Once the students were recruited and randomly divided into two groups, they all underwent a five-week teaching period. There were two one-hour sessions each week. In total, participants were exposed to 12 hours of teaching throughout the intervention. The control and experimental groups received different forms of instruction. Although both groups were exposed to the same vocabulary items and idioms throughout the teaching period, students' attention was drawn to different semantic aspects of words. The teaching sessions for the control group focused mainly on three aspects:

1. The use of dictionaries and understanding of dictionary meaning;

2. The difference between literal and metaphorical meanings of words;

3. The identification of metaphorical meanings of words in sentences.

The instruction for the experimental group followed systematic teaching of different elements underpinning metaphorical words. Such systematic procedure can be observed in the following table. 
TABLE 1:

DESCRIPTION OF THE METHODOLOGICAL PROCEDURE IMPLEMENTED OVER THE FIVE-WEEK PERIOD

\begin{tabular}{|c|c|}
\hline \multirow[t]{2}{*}{ Week 1} & $\begin{array}{l}\text { Session 1: } \\
>\end{array} \quad$ Pretest administered \\
\hline & $\begin{array}{ll}\text { Session 2: } \\
>\quad \text { Use of dictionary } \\
>\quad & \text { Develop familiarity with different dictionary meanings }\end{array}$ \\
\hline \multirow[t]{2}{*}{ Week 2} & $\begin{array}{ll}\text { Session 3: } & \\
> & \text { Use of dictionary } \\
> & \text { Identification of literal and metaphorical meanings of words }\end{array}$ \\
\hline & $\begin{array}{ll}\text { Session 4: } & \\
> & \text { Familiarity with terms (conceptual metaphor, concrete domain and abstract domain) } \\
> & \text { Definition of terms - conceptual metaphors and to distinguish concrete from abstract domains } \\
> & \text { Journal 1 for both groups (control and experimental) }\end{array}$ \\
\hline \multirow[t]{2}{*}{ Week 3} & $\begin{array}{l}\text { Session 5: } \\
>\quad \text { Session } 4 \text { procedure was replicated }\end{array}$ \\
\hline & $\begin{array}{l}\text { Session 6: } \\
>\quad \text { Students are introduced to a variety of conceptual metaphors }\end{array}$ \\
\hline \multirow[t]{4}{*}{ Week 4} & $\begin{array}{l}\text { Session 7: } \\
\text { metaphoricity }\end{array}$ \\
\hline & $>\quad$ Students discuss in groups the above lexical items \\
\hline & $\begin{array}{l}\text { Students are presented with metaphorical words in sentences and are asked to judge their } \\
\text { metaphoricity }\end{array}$ \\
\hline & Students discuss in groups the above lexical items \\
\hline \multirow[t]{2}{*}{ Week 5} & $\begin{array}{l}\text { Session 9: } \\
>\quad \text { Posttest is administered }\end{array}$ \\
\hline & $\begin{array}{l}\text { Session 10: } \\
\quad \quad \text { Journal } 2 \text { for both groups } \\
>\quad \text { Feedback and test scores are provided and discussed with students }\end{array}$ \\
\hline
\end{tabular}

The sessions were oriented towards raising learners' awareness of the underlying relationships between the source and target domain of a metaphor. Those lexical items and idioms which did not have the traditional form of a conceptual metaphor as $A$ is $B$, where $\mathrm{B}$ is the source while $\mathrm{A}$ is the target domain, were also presented to the experimental group as being metaphorically motivated by the same experiential and sensorimotor principles underlying the traditional $A$ is $B$ conceptual metaphor.

The following sections report on the findings from the vocabulary tests as well as the responses to the journal entries.

\section{FINDINGS AND DisCUSSION}

Having analysed the test data, one can observe that the teaching intervention program influenced learners' lexical learning in the experimental group. The figure below shows the pretest and posttest results of the control group.

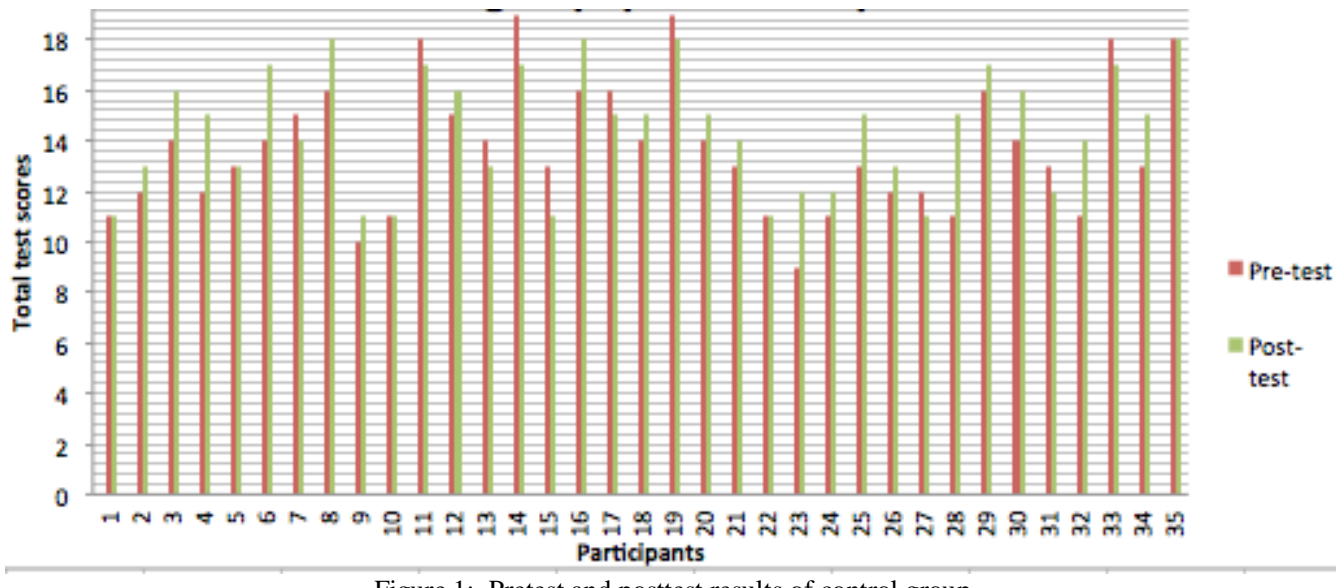

Figure 1: Pretest and posttest results of control group

A closer look at the data reveals some improvement in the scores. The average values of the posttest scores (M=17.3) are greater than the central tendency in the pretest $(M=14.9)$. Although the learners in the control group did not receive explicit instruction of the lexical and conceptual systematicities underpinning conceptual metaphors, they showed differences in their test performance.

A brief summary of the findings by describing the general tendencies is observed in Table 2 which shows the most commonly used measures of central tendency. 
TABLE 2:

PRETEST AND POSTTEST MEAN SCORES AND STANDARD DEVIATIONS OF THE CONTROL GROUP

\begin{tabular}{|lll|}
\hline Measures & Pretest & Posttest \\
\hline Count & 35 & 35 \\
\hline Mean & 13.7 & 14.4 \\
\hline SD & 2.6 & 2.3 \\
\hline Mode & 11 & 15 \\
\hline
\end{tabular}

The table provides a clearer overview of the variations in the students' test scores. Although these are rather selfexplanatory, it is worth highlighting that the most frequently occurring score in the posttest was 15 , and only 11 in the pretest. Despite the absence of an explicit treatment of concptual metaphor and its underpinning systematicities, this clearly points to a developed capacity in the learners' understanding of metaphor.

The application of a systematic procedure aimed at drawing learners' attention to the underlying domains of metaphor had an impact on learners' overall understanding of metaphorical words. This is reflected in Figure 2 which shows an overall improvement in test scores for most students.

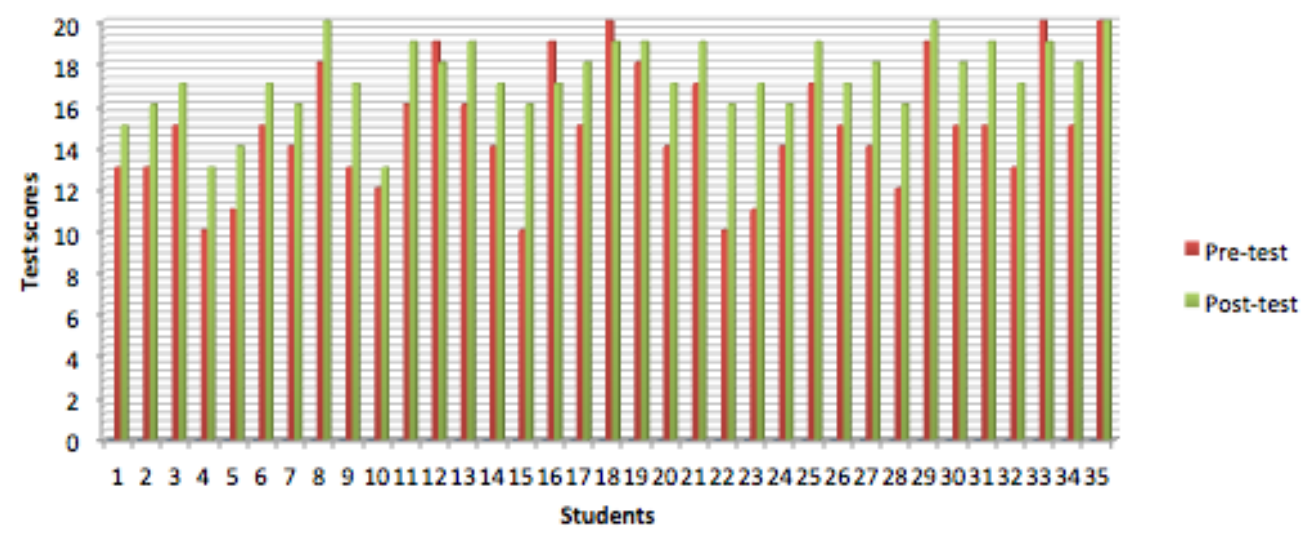

Figure 2: Pretest and posttest results of experimental group

Looking more closely at the data in the above figure, one can observe that just a few learners (12, 16 and 18) scored higher in the pretest than in the posttest. Although it is unknown to the researcher in this study what contributed to this opposite trend in comparison with the rest of the learners, one could speculate that the critical factor contributing to learners' overall improvement of lexical metaphor understanding was not familiarity with the same test used twice (pretest and posttest).

The table below provides a synthesis of descriptive measures of central tendencies in the experimental group's analysed data.

TABLE 3:

PRETEST AND POSTTEST MEAN SCORES AND STANDARD DEVIATIONS OF THE EXPERIMENTAL GROUP

\begin{tabular}{|lll|}
\hline Measures & Pretest & Posttest \\
\hline Count & 35 & 35 \\
\hline Mean & 14.9 & 17.3 \\
\hline SD & 2.9 & 1.8 \\
\hline Mode & 15 & 17 \\
\hline
\end{tabular}

First, of interest is to observe that 15 was the score that occurred most frequently in the pretest in this group, while only 11 in the control group's pretest scores. Even more interesting is to see that the control group's posttest score of most frequency was 15 , which was the frequent score in the pretest results of the experimental group. This table also shows another interesting tendency, that which relates to the average distance of the scores from the mean. The SD, for example, in the pretest results was almost 3 , while in the posttest 1.8 , thus indicating that test results after the teaching intervention period were more homogeneous, and that less variation, or average distance, was observed in relation to the mean.

In looking at the average scores, it can be seen that the variation between pretest and posttest results was greater in the experimental group than in the control group. This is indicative of a possible influence of the approach to metaphor on learners' understanding of metaphorical lexis. To determine whether or not the increase of the experimental group in the posttest scores was statistically significant, a paired-samples t-test was computed on the data. As Dörnyei (2007, p. 215) states "this procedure examines different results obtained from the same group". In this way, such statistical test was carried out to compare the test scores of students in the experimental group before and after the teaching intervention period. There was a significant difference in scores for the pretest $(M=14.91 ; S D=2.95)$ and posttest $(M=17.31 ; S D=1.81), t(7.4833),=-2.40, p<.05$. 
In an attempt to compare the scores of the group that underwent teaching intervention with those of the control group, an independent-sample t-test was computed on the data sets. A summary of the statistics can be seen in Table 4 .

TABLE 4:

RESULTS OF INDEPENDENT-SAMPLE T-TEST

\begin{tabular}{|c|c|c|c|c|c|}
\hline Mean $_{\mathrm{a}}-$ Mean $_{\mathrm{b}}$ & $\mathrm{t}$ & $\mathrm{df}$ & $\mathrm{P}$ & one-tailed & $<.0001$ \\
\hline-2.8571 & -5.67 & 68 & & two-tailed & $<.0001$ \\
\hline
\end{tabular}

The results of the statistics computed on the scores of the control group's posttest $(M=14.457 ; S D=2.368)$, and the scores of the experimental group's posttest $(M=17.313 ; S D=1.811), \mathrm{t}(-5.67)$, showed great statistical significance at $\mathrm{p}<0.001$. This significance points to the potential impact of an awareness-raising tool on the teaching and learning of metaphorical lexis. It seems that drawing learners' attention to the underlying metaphorical patterns of words impacted students' capacity to identify the metaphoricity involved in words, to discriminate literal from metaphorical meanings, and to better comprehend their meanings, which in turn contributed to their overall lexical learning.

Aside from the numerical improvement as evidenced by the vocabulary tests, learners' reflections recorded in their written entries shed some light on the developmental changes in students' views and understandings of metaphor in relation to vocabulary.

\section{STUdents' JouRnAl REFLECTIONS}

Analysis of learners' reflections through the journal entries showed an interesting development in the students' perceptions of metaphor, and of its relevance to vocabulary learning. Although the control and experimental groups dealt with metaphor differently during the intervention period, it is worth noting that several similarities were found in their comments, which are reflected in the following themes that emerged from the data. The following are the two most salient themes in the first journal to both groups.

1. Complexity of some lexical items

2. The value of dictionaries

\section{A. Theme 1: 'Complexity of Some Lexical Items'}

A rather common underlying assumption in students' responses points in the direction that the difficulty in understanding metaphor in English lies in the nature of words, where some, according to students, are more difficult than others. This is observed in the following comments:

'I think it's difficult for me to understand metaphors simply because some words in English are more difficult, those words that are more similar that my own language are more easier to understand and understand the metaphors too' (Student 5, Journal 1, Control group).

The difficulty to understand metaphors is associated with the complexity of some words in English. A similar observation is made by another learner:

'In my language there are lots of metaphor words, and I know them, I can use them and remember all of them, but in English is different. I think English has more words than in my own language so it's more difficult to learn all the words and remember the literal or metaphor meanings' (Student 8, Journal 1, Experimental group).

Reference is made to the metaphorical words the learner knows in his L1. The complexity in learning and remembering metaphors in English is attributed to the English language having a greater lexicon. This perception seems to be held by another student who provides a specific example of how English seems to be a lexically richer language than his own.

'In my language I only know one word for walk, which is camminare, but in my English class I learnt so many different ways like pace, stroll, stride, walk, and others, so I believe it's more difficult to learn the metaphors because of the specific vocabulary in English' (Student 12, Journal 1, Experimental group).

In answering the second question in the journal, two themes emerged from the analysis of responses. One was the learners' overall intention to know more about metaphor, and the other was in relation to the centrality of vocabulary to the overall improvement of language skills.

\section{B. Theme 2: 'the Value of Dictionaries'}

By the time the experimental group wrote their first journal (week 2, session 4), students had been instructed mainly on two key things: first, learners were encouraged to pay close attention to how literal and metaphorical meanings are presented in dictionaries, and, second, key concepts relating to conceptual metaphor were introduced to them. Acknowledging the importance of these two procedures, some learners commented that:

'I think that using the dictionary in a good way is really important because we are not used to it' (Student 8, Journal 1, Experimental group).

Coming to acknowledge the value of using dictionaries well is important as most language learners' main resource for meaning, at least in classroom contexts, is the dictionary. Similar comments are found in entries from the control group where one stated that: 
'I always thought that using a dictionary was a really simple thing, it's not difficult actually but we need to know that some meanings are more common than others and maybe the least use words have more metaphor meaning' (Student 6 , Journal 1, Control group).

It seems that student 6 is beginning to understand that some word meanings are more salient than others. However, his perception of the presence of metaphorical meanings in the least frequently used words is in opposition to the very pervasive nature of metaphor in language and thought (Evans \& Green, 2006; Lakoff \& Johnson, 1980a, 1980b; Tyler \& Evans, 2003).

Close attention to dictionary meanings enabled students to not only differentiate between literal and metaphorical, but to appreciate the examples provided in dictionary entries as "windows to other metaphors". The following student indicated that:

"If I pay a lot of attention to the meanings in the dictionary I can see that some meanings are more literal and some not. I can see the same thing in the examples, and these help me to think about other sentences of metaphor in my own language" (Student 9, Journal 1, Experimental group).

Another similar comment is found in student 11 entry:

"When I was looking for the word path in the dictionary I understood that for example 'my path to success' is a metaphor because a path is way to somewhere" (Student 14, Journal 1, Experimental group).

Both these learners seem to value the systematic use of dictionaries in having access to literal and metaphor meanings. Not only has the dictionary provided knowledge of word 'meaning' but of use.

"I think these teaching classes so far can help me to learn about the meanings that I can get from the dictionary and how can I use them, this is important for us" (Student 4, Journal 1, Control group).

In the experimental group a similar observation was made by student 17 :

"One thing that I have learnt in this class is that the dictionary can give me a lot of things, not just the pronunciation and meaning but also the real examples of the way we can use the metaphor words in real life" (Student 17, Journal 1, Experimental group).

The learner's comment relates closely to the elements of lexical knowledge involved in a word. Nation (2001) indicated that learning a word entails learning its form, meaning and use. It is interesting that the learner has come to realize that the example sentences in dictionary entries provide some knowledge base of how certain words, especially metaphorical, can be used in different contexts.

By the time students wrote their second journal entry (week 5, session 10), the nature of their responses reflected the ways in which the teaching sessions had changed their perceptions of metaphor. The emerging themes in students' second journal are as follows:

1. Learn and experience metaphors

2. Metaphors everywhere

\section{Theme 1: 'Learn and Experience Metaphors'}

The first question in journal 2 related to the ways in which the teaching sessions helped students have a better understanding of metaphor. Students in the control group generally commented that metaphor was important, and that they needed to learn more about them.

"I think I learned that it's important to identify metaphorical and literal words for our understanding of messages, like written or oral, and that I have to learn more about metaphor" (Student 6, Journal 2, Control group).

Since one of the aims of the sessions for the control group focused on differentiating literal from metaphorical meanings as well as their identification in sentences, this student seems certain that our use of language can be literal or metaphorical, and that being able to distinguish them is important for comprehension. That the student expresses a wish to learn more about metaphor is a good indication of the learner's recognition of how central metaphor is to his lexicon and, perhaps, overall language skills.

The systematic and explicit exposure to patterns underlying conceptual metaphor seems to have enabled students in the experimental group to develop an understanding that metaphor is not just a linguistic phenomenon, but one that bases its essence and nature on how we experience the world and interact with it. Our own experiences and interactions with the world are central to how our conceptual system is shaped.

"I remember that in my primary and high school lessons I study some metaphors so when I was learning about metaphor in this classes it came to my mind all the metaphors in my language that I learned when I was young" (Student 13, Journal 2, Experimental group).

Although the learner does not make explicit mention of what has been learnt in the intervention sessions, it is interesting how he intersects his prior learning experiences of metaphor with his current experience in the teaching sessions. A more clearly articulated observation is seen in the following comment:

"the classes are very useful because I can understand that the literal meanings are connected with the metaphorical meanings, that the metaphor we use come from the way we think about the world" (Student 18, Journal 2, Experimental group).

Another learner in the same experimental group made a very clear observation on how her perceptions about metaphor changed over time: 
"At the beginning of the classes I didn't know the reason of learning metaphor because I thought it was a vocabulary class, but after all the classes, practice and texts that we used in the class I realise that I use more metaphors than what I believe in the past and that we need to have more experience with the metaphor for we can learn more" (Student 15, Journal 2, Experimental group).

These comments reveal interesting aspects of how the teaching sessions have shaped learners' understanding of metaphor. Their views of metaphorical language are no longer confined to arbitrary aspects of language, but evidence developed reasoning and an enhanced awareness of the experiential basis of metaphor and of the role of metaphor in language, and in particular, in vocabulary learning.

\section{Theme 2: 'Metaphors Everywhere'}

Referring back to a learner's comment (student 8, experimental group) where he expressed that "English has more words than in my language" and this made it more difficult to learn and remember metaphors in English, his perception of metaphor has now changed:

"I think so, my perceptions have changed in this time because I understand that metaphors are everywhere and that they are not difficult. We just have to be more aware about their existing, and I think that every language have metaphors and all people speak and think in metaphor ways" (Student 8, Journal 2, Experimental group).

This reflection evidences the ways in which the teaching sessions have shaped the learner's understanding of metaphor. Besides the learner's explicit aknowledgement of change in his perceptions, the student seems to now understand that metaphor is a pervasive phenomenon in all languages. A rather similar comment is made by another student in the experimental group.

"Yes I think I have changed my perceptions for different reasons, one because now I understand very well that all the language is metaphoric, and that every culture and language has metaphors, and also that all the texts that people read also have a lot of metaphor. I think that when I read next time I will try to find the metaphors" (Student 13, Journal 2, Experimental group).

The ubiquity of metaphor is acknowledged and appraised by a student who makes a rather critical observation on the meanings conveyed through metaphor:

"my views are changed and I will try to use this change in my views in teaching my students, I will try to use materials with metaphors and teach my students that metaphors are everywhere, in the newspapers, books and coursebooks of whatever topic" (Student 19, Journal 2, Experimental group).

Unlike the clear changes observed in the perceptions of metaphor held by students in the experimental group, learners in the control did not specifically point to a change in their views; rather, general comments on the learning of metaphorical words were made. The following quote is a clear example of this:

"I believe I have to learn more metaphors and I really think I learn more in this course. Maybe in the future I can learn more because it's a good way for expanding my vocabulary and for understanding people and other texts" (Student 7, Journal 2, Control group).

Of a similar kind is the observation and response given by the following learner:

"I believe that I have changed my thinking, I think about the metaphors as really useful for improving my reading skills and before I didn't think this way. And I also change that the vocabulary in the dictionaries can also give you a lot of meanings about the metaphor word, and this I din't really know" (Student 5, Journal 2, Control group).

As can be observed, students in the control group did not clearly address the second question in journal 2 . No mention is made of whether (and if) their perceptions of metaphor changed over time. Their comments, just like in previous responses, show a rather strong inclination to only relating metaphor to vocabulary, but not particulary to the experiential basis of metaphorical language and thinking.

The nature of responses by students in the experimental group reveals clearly the powerful ways in which the teaching intervention period have shaped learners' perceptions, understandings and positions towards metaphor, especially in relation to the learning vocabulary.

All in all, the analysis of the students' voice as evidenced by samples of their journal responses, especially those by students in the experimental group, shed some intersting light on the posible benefits of a metaphor awareness-raising teaching tool. This is ratified by several researchers (e.g. Boers, 2004; Charteris-Black, 2000; Deignan et al., 1997) who have shown that an enhanced knowledge of metaphors has a positive influence on students' capacity to acquire metaphorical vocabulary.

\section{CONCLUSION AND IMPLICATIONS}

This paper set out to examine ESL learners' learning and understanding of metaphorically-used words. In particular, this study was designed to determine the effects of metaphor awareness on students' improvement of lexical learning. From a quantitative perspective, some of the most significant findings to emerge from this study are that the experimental group's test scores were statistically significant and, therefore, higher than what the learners scored in the pretest, thus indicating a possible influence of the metaphor-awareness teaching intervention on the students' ability to understand and learn metaphorical vocabulary. From a qualitative stance, students' responses to journal entries revealed 
not only the complex ways in which learners engaged with metaphor throughout the teaching period, but the changes and development of their views and understandings of metaphor in relation to vocabulary learning.

The findings of this investigation have significant implications for both the understanding of metaphor in English language teaching and learning and the teaching of metaphor in diverse language teaching and learning contexts. Firstly, the students' voice in the first journal was quite clear in reiterating the observed difficulty of metaphorical language. This points to the necessity to implement approaches to vocabulary teaching that deal systematically with the experiential basis of metaphor, thus enabling learners to understand metaphor as an everyday phenomenon of language and thought, not as a complex lexical or literary process. Secondly, in the process of implementation, English language teachers must make informed decisions as to how metaphorical lexis will be introduced to students. In general, figurative language, being metaphor the most pervasive form, has traditionally been pedagogically dealt with as fixed expressions that are learnt mainly through rote learning and memorisation (Chen \& Lai, 2012, p. 239). For this reason, it is pivotal that metaphor be treated systematically rather than in arbitrary ways. To see this crystalised, it is important to call for a change in attitudes and practices towards the teaching of vocabulary. Although the successful introduction and wide acceptance of the lexical approach re-shaped our views and understandings of what is involved in learning a word, much of what we see in English language textbooks and find in teachers' pedagogical practices reflects traditional approaches to vocabulary teaching, which, to a great extent, continue to view it as incidental to the overall purpose of language teaching.

\section{APPENDIX A}

\section{Vocabulary test}

Name: Nationality:

This test has three sections. You have 30 minutes to complete the test.

I. Read the sentences below and decide if the word in bald is used literally or metaphorically in the sentence.

1. Students flooded on to the counter to get discounted tickets for the field trip.
$\square$ Metaphorical
$\square$ Literal

I don't know

2. Italy is a fabulous country. Venice is definitely worth a whole week.
$\square$ Metaphorical
$\square$ Literal
$\square$ I don't know

3. I went to visit a close friend of mine last weekend.
$\square$ Metaphorical
$\square$ Literal
$\square$ I don't know

4. I've got my hands full at the moment. I don't think I can do two jobs at the moment.
$\square$ Metaphorical
$\square$ Literal
$\square$ I don't know

5. My dad believes that it's always important to dive right into the problem.
$\square$ Metaphorical
$\square$ Literal
$\square$ I don't know

6. I didn't know what to say in front of the audience. I was completely lost for words.

$\square$ Metaphorical

$\square$ Literal

I don't know

7. We've been going through some touch moments. We need a shoulder to cry on.

$\square$ Metaphorical
$\square$ Literal

$\square$ I don't know

8. When I was at the party I felt completely out of place.

$\square$ Metaphorical
$\square$ Literal

$\square$ I don't know

9. Hey, Paul! I couldn't take your call because I was in the middle of something.

$\square$ Metaphorical
$\square$ Literal
$\square$ I don't know


10. There's another call for applications to exchange programs in Europe. It's certainly a golden opportunity for undergraduate students.

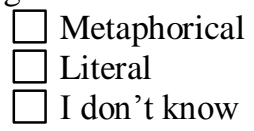

II. Fill in the gaps: Use one of the following words in each space to complete the sentences. Please note there are four distracters in this group of words.

fish - fuel - ways - heart - brakes - dream - paths - steam - red light

1. Unfortunately I missed my friend's ride to university this morning so I had to do it under my own

2. There was nothing in common between us, so it was a good decision to cancel the wedding. He was certainly not the man after my own

3. Buying cloths for no reason? I got tired of doing that. I can now save more because I have put the on spending.

4. I didn't like him at first. He seemed a real cold

5. I believe their marriage has come to an end. Someone told they've gone their separate

III. Idioms: What is your understanding of the following idioms in bold? Write down your ideas of what these idioms mean. You don't have to write long answers.

1. If you want to do it, I am not going to stand in your way.

\section{The police turned a blind eye to it.}

3. They stayed together through thick and thin.

\section{He's running out of steam.}

\section{I am well on the road to recovery.}

\section{APPENDIX B}

\section{Journal Entry 1}

Please reflect on the following two questions and write as much as you can.

1. How easy or difficult has it been for you to understand metaphorical words?

2. In what ways have the teaching sessions helped you better understand metaphorical words?

\section{APPENDIX C}

\section{Journal Entry 2}

Please reflect on the following two questions and write as much as you can.

1. In what ways have the teaching sessions helped you better understand metaphorical words?

2. Have your perceptions of learning metaphorical words changed over time?

\section{REFERENCES}

[1] Anderson, J. R. (1982). Acquisition of cognitive skill. Psychological Review, 89, 369-406.

[2] Beréndi, M., Csábi, S., \& Kövecses, Z. (2008). Using conceptual metaphors and metonymies in vocabulary teaching. In F. L. Boers, S. (Ed.), Cognitive Linguistic Approaches to Teaching Phraseology (pp. pp. 65-69). Berlin Mount de Gruyter.

[3] Boers, F. (2004). Expanding learner's vocabulary through metaphor awareness: What expansion, what learners, what vocabulary? . In M. Achard \& S. Niemeier (Eds.), Cognitive Linguistics, Second Language Acquisition, and Foreign Language Teaching. Berlin Mouton De Gruyter.

[4] Borovsky, A., Kutas, M., \& Elman, J. L. (2013). Getting it right: Word learning across the hemispheres. Neuropsychologia, 51, 825-837.

[5] Carston, R. (2011). Truth-conditional semantics In M. Sbisa, J. O. Östman, \& J. Verschueren (Eds.), Philosophical Perspetives for Pragmatics Amsterdam: John Benjamins Publishing Company.

[6] Charteris-Black, J. (2000). Metaphor and vocabulary teaching in ESP Economics. English for Specific Purposes: An International Journal, 19(2), 149-165.

[7] Chen, Y., \& Lai, H. (2012). EFL learners' awareness of metonymy-metaphor continuum in figurative expressions. Language Awareness, 21(3), 235-248.

[8] Cohen, L., Manion, L., \& Morrison, K. (2007). Research methods in education (Sixth ed.). New York Routledge. 
[9] Creswell, J. (2003). Research design: qualitative, quantitative, and mixed methods approach (2nd ed.). London: SAGE Publications.

[10] Dawson, K. (2009). Introduction to Research Methods: A Practical Guide for Anyone Undertakling a research Project (4th ed.). Oxford How to Books.

[11] Deignan, A. (1999). Corpus-based research into metaphor. In L. Cameron \& G. Low (Eds.), Researching and applying metaphor (pp. 177-199). Cambridge: Cambridge University Press.

[12] Deignan, A., Gabrys, D., \& Solska, A. (1997). Teaching English metaphors using cross-linguistic awareness raising activities. ELT journal, 51, 352-360.

[13] Dobao, A. (2014). Vocabulary learning in collaborative tasks: A comparison of pair and small group work. Language Teaching Research, 18(4), 497-520.

[14] Dörnyei, Z. (2007). Research methods in applied linguistics: quantitative, qualitative and mixed methodologies. Oxford: Oxford University Press.

[15] Elgort, I., \& Warren, P. (2014). L2 vocabulary learning from reading: Explicit and tacit lexical knowledge and the role of learner and item variables. Language Learning, 64(2), 365-414.

[16] Evans, V., \& Green, M. (2006). Cognitive linguistics: An introduction. Edinburgh: Edinburgh University Press.

[17] Frishkoff, G. A., Collins-Thompson, K., \& Perfetti, C. A. (2008). Measuring incremental changes in word knowledge: Experimental validation and implications for learning and assessment. Behavior Research Methods, 40, 907-925.

[18] Gao, \& Meng, G. (2010). A study on the effect of metaphor awareness raising on Chinese EFL learners' vocabulary acquisition and retention. Canadian Social Science, 6(2), 110-124.

[19] Giora, R., \& Fein, O. (1999). On understanding familiar and less-familiar figurative language. Journal of Pragmatics, 31, 1601-1618.

[20] Glucksberg, S. (2003). The psycholinguistics of metaphor. TRENDS in Cognitive Sciences, 7(2), 92-96.

[21] Guo, S. (2007). Is idiom comprehension influenced by metaphor awareness of learners?A case study of Chinese EFL learners. The Linguistics Journal, 3(3), 148-166.

[22] Huckin, T., \& Coady, J. (1999). Incidental vocabulary acquisition in a second language. Studies in Second Language Acquisition, 21, 181-193.

[23] Hulstijin, J. (2001). Intentional and incidental second language vocabulary learning. In P. Robinson (Ed.), Cognitiion and second language instruction (pp. 258-286). Cambridge: Cambridge University Press.

[24] Kalyuga, M., \& Kalyuga, S. (2008). Metaphor awareness in teaching vocabulary. Language Learning Journal, 36(2), $249-257$.

[25] Katz, A., Cacciari, C., Gibbs, R., \& Turner, M. (1998). Figurative language and thought. New York/Oxford Oxford University Press.

[26] Kövecses, Z., \& Szabo, P. (1996). Idioms: A view from Cognitive Semantics Applied Linguistics, 17(3), 326-355.

[27] Lakoff, G., \& Johnson, M. (1980a). Conceptual metaphor in everyday language. The Journal of Philosophy, 77(8), 453-486.

[28] Lakoff, G., \& Johnson, M. (1980b). Metaphors We Live By. Chicago University of Chicago Press.

[29] Lakoff, G., \& Johnson, M. (1999). Philosophy in the Flesh: The Embodied Mind and the Challenge to Western Thought. New York Basic Books

[30] Lewis, M. (1993). The lexical approach. Hove: Language Teaching Publications.

[31] Milton, J. (2009). Measuring second language vocabulary acquisition. Bristol: Multilingual Matters.

[32] Nassaji, H. (2004). The relationship between depth of vocabulary knowledge and L2 learners' lexical inferencing strategy use and success. The Canadian Modern Language Review, 61, 107-134.

[33] Nation, P. (2001). Learning vocabulary in another language. Cambridge: Cambridge University Press.

[34] Nation, P. (2015). Principles guiding vocabulary learning through extensie reading. Reading in a Foreign Language, 27(1), 136-145.

[35] Nowbakht, M., Moinzadeh, A., \& Dabaghi, A. (2015). Issues in vocabulary learning and teaching. 5(2), 247-259.

[36] Read, J. (2000). Assessing vocabulary. Cambridge: Cambridge University Press.

[37] Schmitt, N. (2008). Instructed second language vocabulary learning. Language Teaching Research, 12(3), 320-363.

[38] Steinberg, J. (1999). Mastering metaphor through poetry. Language Arts, 76(4), 324-331.

[39] Tyler, A., \& Evans, V. (2003). The semantics of English prepositions: Spatial scenes, Embodied meaning and Cognition. Cambridge: Cambridge University Press.

[40] Waring, R., \& Takaki, M. (2003). At what rate do learners learn and retain new vocabulary from reading a graded reader. Reading in a Foreign Language, 15, 130-163.

[41] Wilkins, D. (1972). Linguistics in language teaching. London: Arnold.

[42] Wode, H. (1999). Incidental vocabulary acquisition in the foreign language classroom. Studies in Second Language Acquisition, $21,243-258$.

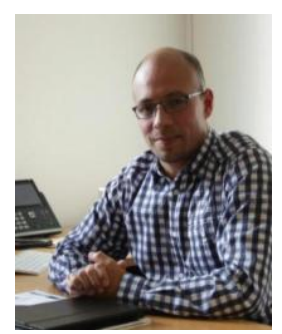

Leonardo Veliz, Ph.D., is Lecturer in TESOL at Deaking University, Melbourne, Australia. He received his Bachelor degree in English teaching and education and his Master in Applied Linguistics. He obtained his $\mathrm{Ph} . \mathrm{D}$. from Deakin University where he currently teaches. Leonardo has extensive experience teaching undergraduate and postgraduate courses in Australia and overseas. His research interests fall broadly within the field of applied linguistics and, more particularly, within the realms of conceptual metaphor and multimodality. He has published several articles in reputable journals. His most recent research projects are on the intersection between visual metaphors and multimodal learning, and on the role of critical reflection in higher education. 